\title{
EXAMINATION OF ACACIA-TREE GASIFICATION PROCESS UNDER VARYING OPERATING PARAMETERS
}

\author{
István BODNÁR ${ }^{1}$, Patrik ISKI², Ádám SKRIBANEK ${ }^{3}$ \\ Institute of Electrical and Electronic Engineering, Faculty of Mechanical Engineering and \\ Informatics, University of Miskolc, Miskolc, Hungary \\ ${ }^{1}$ vegybod@uni-miskolc.hu \\ 2 iskip95@gmail.com \\ 3 skribike@gmail.com
}

\begin{abstract}
This paper presents the thermokinetic modeling of the gasification process performed on the acaciatree under varying operating circumstances and different humidity levels. Gasification does not produce flue gas, but due to imperfect burning, synthesis gas appears which is rich in flammable components $\left(\mathrm{CO}_{2}\right.$ and $\left.\mathrm{H}_{2}\right)$. The chemical structure of this gas depends on the components of the fuel and the humidity level, but is also greatly affected by the technological parameters, such as pressure and temperature, as well as the air-ratio. The study shows the change of chemical composition, fuel value and the reaction efficiency as a function of varying gasification temperature and pressure. Rising temperature results in improved efficiency, while higher pressure worsens reaction efficiency. However, at higher temperature intervals, the effect of the pressure is neglectable.
\end{abstract}

Keywords: acacias, gasification, temperature, air-ratio, reaction efficiency.

\section{Introduction}

Nowadays one of the most important research fields is energetics, which deals with energy production, energy use and the improvement of efficiency. We often hear about gasification technology and wood-gas boilers taking part in heat energy production. Gasification technology is not only able to produce heat, but electricity too, as the main product of gasification is the combustible synthesis gas which can be used by gas motors and turbines with high efficiency. Gas-powered machines are often sensitive to the gas composition and quality parameters, therefore the examination of wood gasification is inevitable. Additionally, wood gasification provides a great opportunity to build wood and biomass fueled quick-start power plants.

\section{Historical review of gasification}

Gasification is one of the oldest processes used to convert solid fossil and renewable fuels into combustible synthesis gas and liquid fuel. This technology was first used by Thomas Shirley, who produced hydrogen in 1659. Robert Gardner filed the first patent in 1788 and the spread of the gasification process began. Its industrial application is associated with William Murdoch and began in 1798 in England and France [1]. 
In the past, combustible gases (wood and carbon gas) were produced from wood and coal, being mainly used for heating and public lighting purposes. By 1850, technology had reached a level of development that allowed $75 \%$ of London's public lighting to be provided with the help of gas produced in this way. Some years later, gasification technology appeared in the United States too, and by 1920, it was used in most cities for heating and public lighting [2].

Following the discovery of the Texas oil fields, the first natural gas pipeline was built in Denver, which eliminated the predominance of synthesis gas. After discovery of oil fields under the North Sea, gas plants spread throughout Europe too. Although the last one was unveiled in England in 1970, we can still find some functioning systems in the third world countries [1].

With the appearance of internal combustion engines, gasification was also used to generate alternative fuels. The first woodgas powered car was designed and built by Thomas Hugh Parker in 1901, but it became widespread only thirty years later. In the 1930s, the rapid development of military industry and the Second World War gave rise to the use of alternative materials in the fuel industry. During the Second World War, the Allies and the Soviet Union did not supply crude oil to European countries, which were occupied by the Germans. Local small-scale exploitation was used by the German army (Wehrmacht). Since there was not enough fuel for the military industry, the Wehrmacht also experimented with wood-gas powered tanks, which were eventually not used because of their difficult and complicated operation. By the end of the Second World War, there were about a half a million wood-gas powered vehicles in Germany alone [1]. There were more than a million such vehicles in Europe. In occupied Denmark, 95\% of civilian and agricultural vehicles were wood-gas powered [2].
The chemical composition and energy content of synthesis gas produced during the gasification of wood was sufficient to become the fuel of the rudimentary internal combustion engine [1]. Some decades later, further developed gasification technology was used in waste management and power plant energy. Special workshops had been set up to transform traditional cars into gaspowered ones, and fuel filling stations were built, where people were able to buy firewood of the right size.

Gasification is a process based on the rapid heat dissipation of materials with partial oxidation and which has a smaller oxygen demand compared to the theoretical oxygen required for the perfect combustion. During the partial oxidation of the organic compounds found in the parent material, synthesis gas is released, which can be utilized either as raw material, chemical synthesis or as fuel [1].

Due to the sensitivity of the process, it is important, that the characteristics (size, moisture content, consistency) of the fuel supplied remain within certain predetermined limits [3]. The effect of sensitivity typically occurs in energetic and environmental efficiency.

The main purpose of the process is to achieve the highest gas output while achieving optimum energy efficiency. The synthesis gas produced during the gasification process is a mixture rich in hydrogen and carbon monoxide which depends on the gasifying medium and which contains energetically inert components. The most commonly occurring non-combustible component is carbon dioxide and water steam, which take part in the operation, but leave the reactor as ballast. The gasifying medium significantly influences the chemical composition and energy content of the resulting synthesis gas. The gasifying medium helps to break down the solid carbon and the higher molecular weight carbon hydrogens resulting in the release of hydro- 
gen and carbon monoxide [2]. Most commonly, air, steam and pure oxygen are used, but a good ratio of carbon dioxide and oxygen can also yield good results. An incorrectly selected auxiliary gas can cause the failure of the technology.

It is recommended to cool the synthesis gas before utilization and subjected to a complex purification process to remove harmful and corrosive substances. The purified synthesis gas is usually used to produce heat energy and electricity by burning it in a gas engine or gas turbine.

Gasification does not exist as a technology on its own, because in a reactor, for this purpose, pyrolysis and combustion zones are both formed. However, the name is appropriate, because in case of thermodynamic equilibrium the reactions, which are taking place, with the exception of radiation losses, result a self-sustaining process [1]. In a thermodynamic equilibrium state, the system does not cool and does not heat up; therefore it does not require heat input (pyrolysis) or heat loss (combustion) and produces combustible synthesis gas. The gasification is carried out in four steps, which happen at different temperatures and stoichiometric proportions in the reactor. The relationships between the zones are determined by the type of the reactor [2].

Gasification is the only thermal treatment technology that can be an endothermic or an exothermic process, depending on the excess air factor and on the temperature. When applying gasification, the main goal is to achieve a self-sustaining process. This only occurs if the reactor, considering the radiation and heat loss, is in a thermodynamic equilibrium state. After the start, the system reaches its steady state after a $5 . .20$ minutes long period. The thermodynamic equilibrium state is significantly affected by the moisture content of the dispersed raw material. The excess air factor value can be determined based on the moisture content and the thermal losses of the reactor.

\section{Basic equations of thermokinet- ic model examination}

During thermokinetic model investigation, the chemical and energetic properties of gases, produced from different materials are determined. The thermokinetic model is used for the modeling of processes, which is based on the law of energy conservation [1]. By applying this model, approximate estimates of the chemical composition, viscosity and other properties of the produced gas can be obtained.

As the essence of the model is to make the calculations faster and easier, some ingredients, such as nitrogen oxide and ethylene, acetylene compounds were neglected during writing the simplified model equations. The model equation is written for the hydrogen and oxygen content of the fuel in one mole of carbon content $[1,5,6]$.

Model examinations were carried out using the equilibrium constants with predetermined gas composition at fixed temperature and operating pressure. The equilibrium transformation determination at the given temperature is the method of the equilibrium constants. Its essence is to determine the composition of the product using the principle of Gibbs's free energy minimization. For the analyses, we used software called Gaseq, which is based on a NASA method. It was developed by Chris Morley and it is publicly accessible (for educational and non-profit purposes). It is mainly used for solving equations describing the interaction of gas reactants. In the case that the rate of the theoretical and used molar oxygen demand equals one $(\lambda=1)$, or higher, we get the combustion equations back.

The expanded model equation, based on the molar theoretical content may be written as follows:

$$
\begin{aligned}
& \mathrm{CH}_{k} \mathrm{O}_{l}+n_{m} \cdot \mathrm{H}_{2} \mathrm{O}+\mathrm{a} \cdot \mathrm{N}_{2}=x_{1} \cdot \mathrm{H}_{2}+x_{2} \\
& \mathrm{CO}+x_{3} \cdot \mathrm{H}_{2} \mathrm{O}+x_{4} \cdot \mathrm{CO}_{2}+x_{5} \cdot \mathrm{CH}_{4}+x_{6}
\end{aligned} .
$$


$\mathrm{O}_{2}+x_{7} \cdot \mathrm{NO}+x_{8} \cdot \mathrm{NO}_{2}+x_{9} \cdot \mathrm{N}_{2}+x_{10} \cdot$

$\mathrm{N}_{2} \mathrm{O}+x_{11} \cdot \mathrm{C}+x_{i} \cdot \mathrm{C}_{d} \mathrm{H}_{f} \mathrm{O}_{g}$

where: $n_{m}$ is the moisture content of the fuel per mole of carbon content; $a$ is the nitrogen content of the fuel, $\mathrm{x}_{1}$ is the molar hydrogen content of the produced raw synthesis gas, $\mathrm{x}_{2}$ is the content of carbon-monoxide; $\mathrm{x}_{3}$ is the content of water steam and $x_{4}$ is the content of carbon-dioxide ; $\mathrm{x}_{5}$ is the content of methane, $x_{6}$ is the residual oxygen content, $x_{7}$ is the nitrogen-monoxide, $x_{8}$ is the content of nitrogen-dioxide, $x_{9}$ is the content of nitrogen; $\mathrm{x}_{10}$ is the dinitrogen-oxide content; $\mathrm{x}_{11}$ is the residual solid carbon; $\mathrm{x}_{\mathrm{i}}$ is the molar amount of other constituents that are formed (e.g.: ethylene, acetylene).

Model examinations were made to determine the chemical composition of gas products and be able to determine the parameters and properties characterizing the technological and energy efficiencies.

Applying the parametric basic equations is necessary because we have built up the model examinations by using them. To determine the right side of equation (1), e.g. to determine the unknown quantities, we have chosen the equilibrium constant method, by knowing the input compositions and the resulting product.

We applied the equilibrium constant method, for which we first wrote the molar material equation for each component, then we checked to see if the molar material retention met (equations 2-4). In the end, the equilibrium conditions were determined (equations 5-6) [1, 6].

Carbon equilibrium:

$1=x_{2}+x_{4}+x_{5}$,

Hydrogen equilibrium:

$k+2 \cdot n_{m}=2 \cdot x_{1}+2 \cdot x_{3}+4 \cdot x_{5}$,

Oxygen equilibrium:

$l+n_{m}=x_{2}+x_{3}+2 \cdot x_{4}+2 \cdot x_{6}$,

Water-gas reaction balance constant:

$$
K_{1}=\frac{x_{1} \cdot x_{4}}{x_{2} \cdot x_{3}},
$$

Methane formation equilibrium constant:

$$
K_{2}=\frac{x_{5}}{x_{1}^{2}}
$$

where: $K_{1}$ and $K_{2}$ are the water-gas and the methane formation equilibrium constants, which are dependent on the temperature and the pressure.

The value expressed in molar amounts of the resulting products is indicated by the equilibrium mole number $(x)$. The equilibrium number shows how the resulting component is generated compared to other product components.

Gibbs's free energy can be written according to equation numbers pressure and temperature in accordance with formula (7) $[1,8]$.

$$
\frac{G}{R \cdot T}=\sum_{i=1}^{n}\left(\frac{x_{i} \cdot G_{i}^{0}}{R \cdot T}+x_{i} \cdot \ln \frac{x_{i}}{\sum x_{i}}+x_{i} \cdot \ln p\right),
$$

where: $G$ the Gibbs free energy, $G_{i}{ }^{0}$ is the specific saturation energy of the i-th material with respect to 1 mole of material at atmospheric pressure, $\mathrm{R}$ is the universal gas constant, $\mathrm{T}$ is the temperature of the system, $\mathrm{p}$ is the pressure of the system, $\mathrm{x}_{\mathrm{i}}$ is equilibrium mole number of component $i$, so the material quantity of the i-th parent material in the blend, $\mathrm{n}$ is the number of chemical elements, $\sum \mathrm{x}_{\mathrm{i}}$ is the sum of the equilibrium numbers of the final product, the amount of the blend materials.

In case of the thermodynamic state, the main purpose is to minimize the G/RT rate, which is determined by the elemental composition.

During the model examinations, we applied the equilibrium constant method, at the pressure and the temperature fixed in the Gaseq software, to solve the model equations. The software was created for analyzing chemical equilibrium processes, so applying it helps in the examination of thermic treatment technologies. During the 
simulations of gasification processes, we were able to see how the variable input parameters determined the composition of the gas produced during the gasification: the composition is really important to know in order to determine the efficiency of power and heat production using the produced gas.

\section{Energy efficiency examination}

Energy efficiency is one of the central topics of our times. Energy efficiency policy is closely related to commercial, industrial and energy security activities, but environmental benefits have become increasingly important as one of the basic tools for reducing carbon emissions [3]. Many conventional and non-conventional measurements are known and applied to determine the efficiency of energy conversion. The following non-conventional parameters are presented.

The reaction, or the chemical efficiency formula (8), shows us what part of the energy content of the solid fuel is in the produced gas product $[9,10]$. By knowing the reaction efficiency, the parameter that characterizes the perfection of combustion can be determined. Its calculation method is shown in formula (9). According to these:

$$
\begin{aligned}
& \eta_{r}=\frac{m_{g t} \cdot F_{g t}}{m_{s z t} \cdot F_{s z t}} \\
& \eta_{\text {lé }}=1-\eta_{\mathrm{r}},
\end{aligned}
$$

where: $\eta_{\mathrm{r}}$ is the reaction efficiency, $\left(m_{\mathrm{gt}}\right)$ is the mass flow of the gas product, $\mathrm{F}_{\mathrm{gt}}$ is the calorific value of the gas product, $\left(\mathrm{m}_{\mathrm{szt}} \cdot \mathrm{f}\right.$ the mass flow of the solid fuel, $F_{\mathrm{szt}}$ is fuel calorific value and $\eta_{\text {é }}$ is the combustion efficiency.

\section{Examination of acacia wood gas- ification}

This study was carried out applying the aforementioned „Gaseq Chemical Equilibrium Program" using the equilibrium constant method. To perform an analysis, it is necessary to have the temperature, pressure and excess air factor values of the given process and the composition of the selected fuel. In this task, in all cases, acacia wood is the fuel. The composition of the dry solid fuel is shown in Table $\mathbf{1}$.

Table 1. The elemental composition of acacia tree of the dry base

\begin{tabular}{|c|c|}
\hline Component name & Amount \\
\hline Carbon content & $49.50 \%$ \\
\hline Hydrogen content & $5.90 \%$ \\
\hline Oxygen content & $43.30 \%$ \\
\hline Nitrogen content & $0.40 \%$ \\
\hline Ash content & $0.90 \%$ \\
\hline
\end{tabular}

In the process of modeling, the elemental molecules in the element must be given, not the elemental elements. The wood is made up of cellulose molecules, which are not included in the software, so cellulose is substituted with phenol. The corrected composition is given in Table 2 .

Following the determination of the above data, the efficiency of the reaction (gasification) was examined on the basis of (8), under different boundary conditions.

Table 2. The composition of the dry acacia corrected with phenol content.

\begin{tabular}{|c|c|}
\hline Component name & Amount \\
\hline Carbon content & $0.000 \%$ \\
\hline Hydrogen content & $1.746 \%$ \\
\hline Oxygen content & $32.311 \%$ \\
\hline Nitrogen content & $0.400 \%$ \\
\hline Ash content & $0.900 \%$ \\
\hline Phenol content & $64.644 \%$ \\
\hline
\end{tabular}

After the determination of the previously introduced data, the efficiency of the calorific value of the released combustible gases in the case of the different parameters by (8) was investigated. The amount of released gas was determined by the aforementioned Gaseq software. Carbon monoxide and hydrogen gases were present in the combustible constituents in a significant amount. 
During these analyses, we examined the gas composition and reaction efficiency change caused by the change of the excess air factor, the temperature of the reaction and the operating pressure.

During this simulation, we varied the temperature between $600{ }^{\circ} \mathrm{C}$ and $1.000{ }^{\circ} \mathrm{C}$, and the pressure between 1-20 bar. The data are summarized in the following tables, then depicted in a diagram. During the test, the moisture content of the acacia tree was kept constant at $15 \%$, while the excess air factor was set to 0.5 . In all cases $1 \mathrm{~kg}$ of acacia was simulated to be gasified.

Table 3. shows that in the case of low temperature, increasing the operating pressure decreases the hydrogen and carbonmonoxide production. As a result, the heating value of the produced wood-gas decreases and the reaction efficiency drastically decreases (Table 4.).

Table 5. and Table 6. contain the results obtained at $700{ }^{\circ} \mathrm{C}$. Depending on the increase in pressure, a decrease in energy efficiency is also observed, but the slope of decrease is lower.

Table 3. Hydrogen and carbon monoxide amounts at $600{ }^{\circ} \mathrm{C}$

\begin{tabular}{|c|c|c|}
\hline $\begin{array}{c}\text { Pressure } \\
\text { [bar] }\end{array}$ & $\begin{array}{c}\text { Hydrogen } \\
\text { content } \\
\text { [kg] }\end{array}$ & $\begin{array}{c}\text { Carbon-monoxide } \\
\text { content } \\
\text { [kg] }\end{array}$ \\
\hline $\mathbf{1}$ & 0.03700 & 0.38466 \\
\hline $\mathbf{5}$ & 0.02339 & 0.19235 \\
\hline $\mathbf{1 0}$ & 0.01809 & 0.13551 \\
\hline $\mathbf{1 5}$ & 0.01539 & 0.11033 \\
\hline $\mathbf{2 0}$ & 0.01367 & 0.09534 \\
\hline
\end{tabular}

Table 4. Heat value and reaction efficiency at $600{ }^{\circ} \mathrm{C}$

\begin{tabular}{|c|c|c|}
\hline $\begin{array}{c}\text { Pressure } \\
\text { [bar] }\end{array}$ & $\begin{array}{c}\text { Wood-gas heat- } \\
\text { ing value } \\
\text { [MJ/kg] }\end{array}$ & $\begin{array}{c}\text { Reaction effi- } \\
\text { ciency [\%] }\end{array}$ \\
\hline $\mathbf{1}$ & 8.3251 & 70.3682 \\
\hline $\mathbf{5}$ & 4.7495 & 40.1458 \\
\hline $\mathbf{1 0}$ & 3.5395 & 29.9174 \\
\hline $\mathbf{1 5}$ & 2.9611 & 25.0292 \\
\hline $\mathbf{2 0}$ & 2.6033 & 22.0049 \\
\hline
\end{tabular}

Table 5. Hydrogen and carbon monoxide content at $700{ }^{\circ} \mathrm{C}$

\begin{tabular}{|c|c|c|}
\hline $\begin{array}{c}\text { Pressure } \\
\text { [bar] }\end{array}$ & $\begin{array}{c}\text { Hydrogen } \\
\text { content } \\
\text { [kg] }\end{array}$ & $\begin{array}{c}\text { Carbon-monoxide } \\
\text { content } \\
\text { [kg] }\end{array}$ \\
\hline $\mathbf{1}$ & 0.03740 & 0.48279 \\
\hline $\mathbf{5}$ & 0.03409 & 0.44707 \\
\hline $\mathbf{1 0}$ & 0.02950 & 0.39625 \\
\hline $\mathbf{1 5}$ & 0.02611 & 0.35773 \\
\hline $\mathbf{2 0}$ & 0.02362 & 0.32876 \\
\hline
\end{tabular}

Table 6. Heat value and reaction efficiency at $700{ }^{\circ} \mathrm{C}$

\begin{tabular}{|c|c|c|}
\hline $\begin{array}{c}\text { Pressure } \\
\text { [bar] }\end{array}$ & $\begin{array}{c}\text { Wood-gas } \\
\text { heating value } \\
\text { [MJ/kg] }\end{array}$ & $\begin{array}{c}\text { Reaction } \\
\text { efficiency } \\
\text { [\%] }\end{array}$ \\
\hline $\mathbf{1}$ & 9.3642 & 79.1514 \\
\hline $\mathbf{5}$ & 8.6062 & 72.7445 \\
\hline $\mathbf{1 0}$ & 7.5421 & 63.7503 \\
\hline $\mathbf{1 5}$ & 6.7463 & 57.0233 \\
\hline $\mathbf{2 0}$ & 6.1549 & 52.0245 \\
\hline
\end{tabular}

Table 7. and 8. contain the results obtained for gasification at $800{ }^{\circ} \mathrm{C}$. The deterioration of energy efficiency caused by the increase of pressure is decreasing. While at $600{ }^{\circ} \mathrm{C}$ the reaction efficiency at 20 bar operating pressure decreased to less than a third compared to the examinations at 1 bar, at $800{ }^{\circ} \mathrm{C}$ this value did not reach $10 \%$.

Table 7. Hydrogen and carbon monoxide amounts at $800{ }^{\circ} \mathrm{C}$

\begin{tabular}{|c|c|c|}
\hline $\begin{array}{c}\text { Pressure } \\
\text { [bar] }\end{array}$ & $\begin{array}{c}\text { Hydrogen } \\
\text { content } \\
\text { [kg] }\end{array}$ & $\begin{array}{c}\text { Carbon-monoxide } \\
\text { content } \\
\text { [kg] }\end{array}$ \\
\hline $\mathbf{1}$ & 0.03438 & 0.52939 \\
\hline $\mathbf{5}$ & 0.03412 & 0.52648 \\
\hline $\mathbf{1 0}$ & 0.03339 & 0.51837 \\
\hline $\mathbf{1 5}$ & 0.03240 & 0.50705 \\
\hline $\mathbf{2 0}$ & 0.03129 & 0.49426 \\
\hline
\end{tabular}

Table 8. Heating value and reaction efficiency obtained at $800{ }^{\circ} \mathrm{C}$

\begin{tabular}{|c|c|c|}
\hline $\begin{array}{c}\text { Pressure } \\
\text { [bar] }\end{array}$ & $\begin{array}{c}\text { Wood-gas } \\
\text { heating value } \\
\text { [MJ/kg] }\end{array}$ & $\begin{array}{c}\text { Reaction } \\
\text { efficiency } \\
\text { [\%] }\end{array}$ \\
\hline $\mathbf{1}$ & 9.4724 & 80.0664 \\
\hline $\mathbf{5}$ & 9.4118 & 79.5543 \\
\hline $\mathbf{1 0}$ & 9.2423 & 78.1215 \\
\hline $\mathbf{1 5}$ & 9.0092 & 76.1509 \\
\hline $\mathbf{2 0}$ & 8.7468 & 73.9331 \\
\hline
\end{tabular}


Table 9. and Table 10. contain the results of gasification at $900{ }^{\circ} \mathrm{C}$. It can be noticed, that the rate of degradation of the reaction rate, caused by the pressure increase, is not even $1 \%$.

Table 9. Hydrogen and carbon monoxide amounts at $900{ }^{\circ} \mathrm{C}$

\begin{tabular}{|c|c|c|}
\hline $\begin{array}{c}\text { Pressure } \\
\text { [bar] }\end{array}$ & $\begin{array}{c}\text { Hydrogen } \\
\text { content [kg] }\end{array}$ & $\begin{array}{c}\text { Carbon- } \\
\text { monoxide con- } \\
\text { tent [kg] }\end{array}$ \\
\hline $\mathbf{1}$ & 0.03179 & 0.56572 \\
\hline $\mathbf{5}$ & 0.03176 & 0.56542 \\
\hline $\mathbf{1 0}$ & 0.03168 & 0.56455 \\
\hline $\mathbf{1 5}$ & 0.03156 & 0.56318 \\
\hline $\mathbf{2 0}$ & 0.03140 & 0.56132 \\
\hline
\end{tabular}

Table 10. Heating value and reaction efficiency obtained at $900{ }^{\circ} \mathrm{C}$

\begin{tabular}{|c|c|c|}
\hline $\begin{array}{c}\text { Pressure } \\
\text { [bar] }\end{array}$ & $\begin{array}{c}\text { Wood-gas } \\
\text { heating value } \\
\text { [MJ/kg] }\end{array}$ & $\begin{array}{c}\text { Reaction } \\
\text { efficiency } \\
\text { [\%] }\end{array}$ \\
\hline $\mathbf{1}$ & 9.5286 & 80.5409 \\
\hline $\mathbf{5}$ & 9.5219 & 80.4849 \\
\hline $\mathbf{1 0}$ & 9.5036 & 80.3294 \\
\hline $\mathbf{1 5}$ & 9.4753 & 80.0908 \\
\hline $\mathbf{2 0}$ & 9.4373 & 79.7697 \\
\hline
\end{tabular}

In the case of gasification at $1000{ }^{\circ} \mathrm{C}$ (Table 11. and Table 12.) the effect of the pressure increase is negligible.

Table 11. Hydrogen and carbon monoxide amounts at $1.000{ }^{\circ} \mathrm{C}$

\begin{tabular}{|c|c|c|}
\hline $\begin{array}{c}\text { Pressure } \\
\text { [bar] }\end{array}$ & $\begin{array}{c}\text { Hydrogen } \\
\text { content [kg] }\end{array}$ & $\begin{array}{c}\text { Carbon- } \\
\text { monoxide con- } \\
\text { tent }[\mathbf{k g}]\end{array}$ \\
\hline $\mathbf{1}$ & 0.02967 & 0.59522 \\
\hline $\mathbf{5}$ & 0.02966 & 0.59516 \\
\hline $\mathbf{1 0}$ & 0.02964 & 0.59503 \\
\hline $\mathbf{1 5}$ & 0.02962 & 0.59482 \\
\hline $\mathbf{2 0}$ & 0.02960 & 0.59454 \\
\hline
\end{tabular}

On the basis of the results obtained, the increase in operating pressure results in the reduction of the efficiency of gasification reaction, but the operating temperature influences in a positive direction. The reaction efficiency decreasing effect of the pres- sure increase in the function of the temperature is exponential. The ideal gasification temperature for acacia is between $800{ }^{\circ} \mathrm{C}$ and $900{ }^{\circ} \mathrm{C}$, because the gas has the best parameters in the case of setting the temperature between these values.

Table 12. Heating value and reaction efficiency obtained at $1.000{ }^{\circ} \mathrm{C}$

\begin{tabular}{|c|c|c|}
\hline $\begin{array}{c}\text { Pressure } \\
\text { [bar] }\end{array}$ & $\begin{array}{c}\text { Wood-gas } \\
\text { heating value } \\
\text { [MJ/kg] }\end{array}$ & $\begin{array}{c}\text { Reaction } \\
\text { efficiency } \\
\text { [\%] }\end{array}$ \\
\hline $\mathbf{1}$ & 9.5721 & 80.9090 \\
\hline $\mathbf{5}$ & 9.5703 & 80.8937 \\
\hline $\mathbf{1 0}$ & 9.5666 & 80.8624 \\
\hline $\mathbf{1 5}$ & 9.5621 & 80.8241 \\
\hline $\mathbf{2 0}$ & 9.5569 & 80.7800 \\
\hline
\end{tabular}

The above is illustrated in Figure 1. One can see how the reaction efficiency changes depending on the gasification temperature and on the operating temperature. It can be seen also that at lower temperatures the operating temperature has a greater effect on the efficiency of the gasification reaction than at higher temperatures.

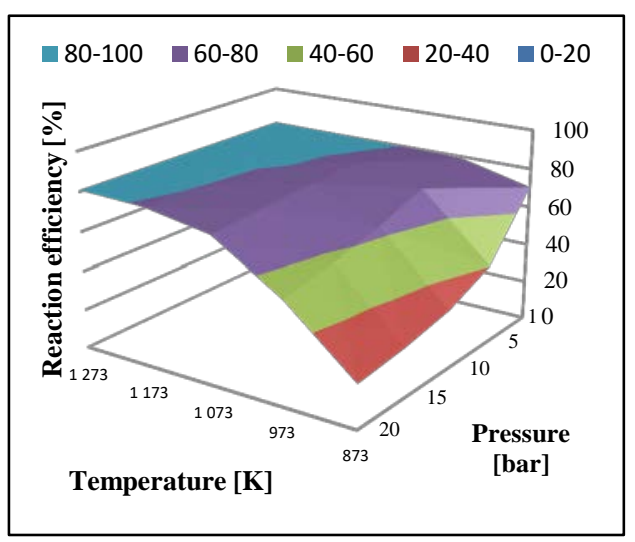

Figure 1. Reaction efficiency depending on the temperature and operating temperature, during acacia gasification

We also investigated how the reaction efficiency changes with constant excess air factor and temperature and with constant moisture fuel. Figure 2. illustrates how the 
reaction efficiency varies depending on the pressure in the case of 0.6 excess air factor. During gasification at $800{ }^{\circ} \mathrm{C}, 15 \%$ is the moisture content of the gaseous acacia wood.

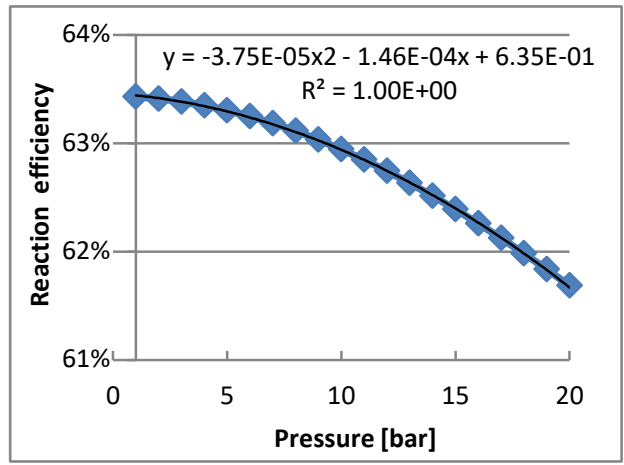

Figure 2. Reaction efficiency as a function of pressure, constant temperature, excess air factor and moisture content

It can be noticed, that the increase in pressure exponentially reduces the efficiency of the reaction, so it is desirable to select an unreasonable high pressure during the gasification. A similar trend can be observed when varying the excess air factor, temperature and moisture content.

We also examined how the efficiency of the reaction changes, if the excess air factor and the moisture content of the solid fuel are varied, while the temperature is constant $800{ }^{\circ} \mathrm{C}$ and the pressure is 1 bar.

It can also be observed that by increasing the excess air factor, the efficiency of the reaction decreases drastically. Increasing the moisture content of the fuel only slightly reduces the efficiency of the reaction. This is illustrated in Table 13. and Figure 3.

Table 13. Gasification reaction efficiencies at $800^{\circ} \mathrm{C}$ temperature and 1 bar pressure.

\begin{tabular}{|c|c|c|c|}
\hline $\begin{array}{c}\text { Moisture } \\
\text { content }\end{array}$ & \multicolumn{3}{|c|}{ Excess air factor [-] } \\
\hline$[\mathbf{\%}]$ & $\mathbf{0 . 5}$ & $\mathbf{0 . 6}$ & $\mathbf{0 . 7}$ \\
\hline $\mathbf{1 0}$ & $80.10 \%$ & $63.65 \%$ & $48.14 \%$ \\
\hline $\mathbf{2 0}$ & $79.49 \%$ & $63.19 \%$ & $47.77 \%$ \\
\hline $\mathbf{2 5}$ & $79.16 \%$ & $62.93 \%$ & $47.58 \%$ \\
\hline
\end{tabular}

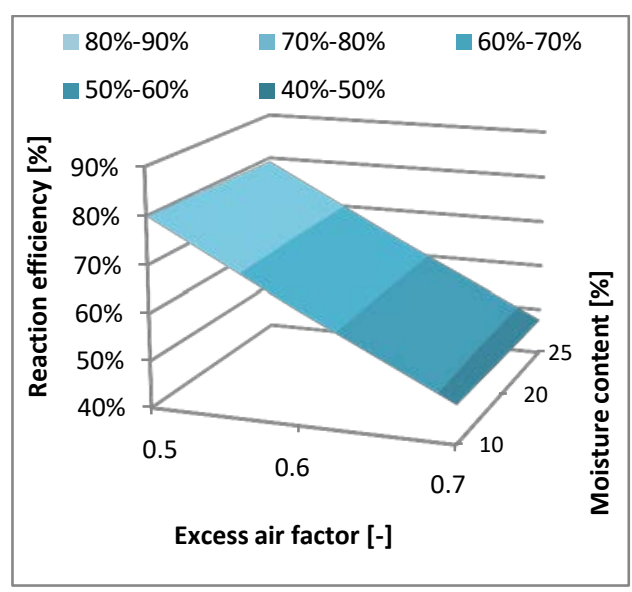

Figure 3. Efficiency at $800{ }^{\circ} \mathrm{C}$ depending on the excess factor and the moisture content.

At the end of the analyses, we investigated how the electricity produced from the synthesis gas from the gasification of the wet wood relates to the electricity produced from the combustion of the wet wood. We call this amount electricity density change. The method of calculation is shown in formula (10).

$$
\Delta e_{v}=\frac{e_{k \text { gasification }} \cdot \eta_{\text {egv } D}}{e_{\text {k combustion }} \cdot \eta_{\text {egv RC }}},
$$

where: $\Delta \mathrm{e}_{\mathrm{rv}}$ is the electricity density change, $e_{k}$ gasification is the specific energy output of the gasification, $e_{k \text { combustion }}$ is the specific energy output of combustion, $\eta_{\text {egv }} \mathrm{i}$ is the electrical efficiency of the Diesel cycle used during gasification, $\eta_{\text {egv RC }}$ is electrical efficiency of the Rankine-Clausius cycle used during the combustion.

The electrical efficiency of the RankineClausius cycle was 27\%, while the energy productions electrical efficiency with the help of a gas engine was 36\%, these amounts are usual. The values obtained are shown in Figure 4. 


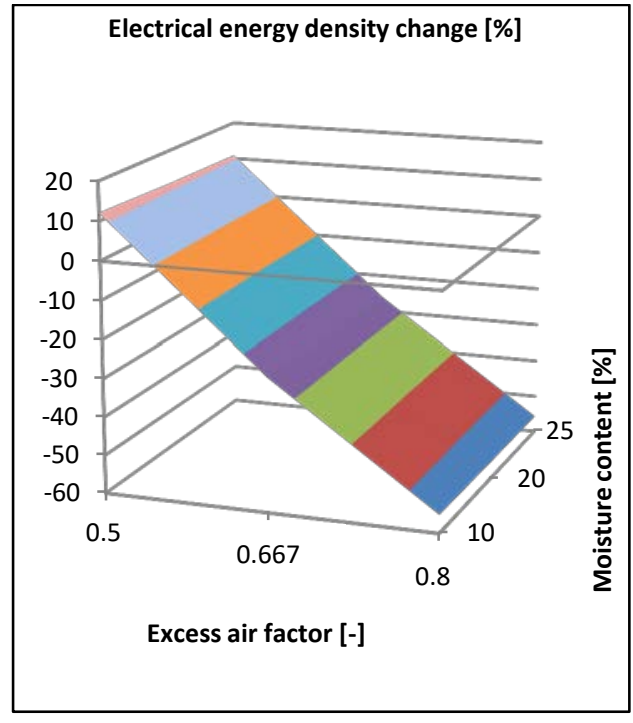

Figure 4. Change in density of electrical energy at $800{ }^{\circ} \mathrm{C}$ depending on the excess air factor and the moisture content.

From Figure 4. it can be seen, that with both increasing excess air factor and moisture content, the energy density change varies in an unfavorable direction. Increasing the excess air factor results in a more intensive change in the density of electricity than the increase in moisture content, therefore in case of a higher moisture content fuel, gasification based electricity production may be favorable.

Above the excess air factor, the energy density change becomes negative, which means that it is not possible to produce more electricity from a unit of fuel using gasification technology, than by using conventional combustion technology.

\section{Conclusion}

During the analyses, we have shown that the simulation of the gasification of woody biomass is complex and complicated. Furthermore, it has become apparent that the moisture content of the raw material, as well as the parameters related to the technology can be influenced greatly by the excess air factor, temperature and pressure, which causes variation in the heating value of the synthesized gas produced. The analyses showed that the moisture content, the excess air factor and the pressure increase result in a reduction in the reaction efficiency, while temperature increase contributes to the increase of the reaction efficiency.

From the results above, we can conclude, that the efficiency of the gasification is the highest in case of selecting the excess air factor as 0.5 . Since the moisture content does not significantly influence the efficiency of gasification, it can be used effectively, in cases where the moisture content of the fuel is relatively high (2025\%).

By increasing the pressure, the efficiency decreases exponentially, so it is not worth choosing high pressure. Increasing the reaction temperature above $800{ }^{\circ} \mathrm{C}$ slightly increases the efficiency of the reaction, so its increase is not purpose-oriented based on economic considerations.

In our opinion, the efficient operation of a power plant, using gasification technology requires a very complex process, and requires careful engineering work, but it is worth using this technology. By applying gasification technology, we are able to build quick-start power plants capable of producing electricity with higher efficiency than in case of conventional incineration.

\section{References}

[1] Zainal Z. A., Ali R., Lean C. H., Seetharamu K. N.: Prediction of performance of $a$ downdraft gasifier using equilibrium modeling for different biomass material. Energy Conversion and Management, 42/12. (2001) 1499-1515. https://doi.org/10.1016/S0196-8904(00)00078-9

[2] Red T. B., Das A.: Handbook of biomass downdraft gasifier engine systems. Solar Energy Research Ins., Golden, Colorado 1988. www.nrel.gov/docs/legosti/old/3022.pdf

[3] Hill T., Dowen S.: Pyrolysis and gasification. Briefing (Draft 2), UK Without Incin- 
eration Network, 2010, 1-9 http://ukwin.org.uk/files/pdf/UKWIN_Pyroly sis_and_Gasification_Briefing_Draft_May_2 010.pdf

[4] Patterson M. G.: What is energy efficiency? Concepts, indicators and methodological issues. Energy Policy, 24/5. (1996) 377-390. https://doi.org/10.1016/0301-4215(96)00017-1

[5] Wang Y., Kinoshita C. M.: Kinetic model of biomass gasification. Solar Energy, 51/1. (1993) 19-25.

https://doi.org/10.1016/0038-092X(93)90037-O

[6] Mountouris A., Voutsas E., Tassios D.: Solid waste plasma gasification: Equilibrium model development and exergy analysis. Energy Conversion and Management, 47/13-14. (2006) 1723-1737.

https://doi.org/10.1016/j.enconman.2005.10.015
[7] Hatzilyberis K. S.: Design of an indirect heat rotary kiln gasifier. Fuel Processing Technology, 92/12. (2011) 2429-2454. https://doi.org/10.1016/j.fuproc.2011.08.004

[8] Morly C.: Method for calculating equilibrium compositions at specified temperature, Gaseq, a chemical equilibrium program for windows. 2005. www.gaseq.co.uk

[9] Rajvanshi K. A.: Biomass gasification. In: Alternative Energy in Agriculture (ed. D. Yogi Goswami), 2. (1986) 83-102. https://www.pssurvival.com/PS/Gasifiers/Bio mass_Gasification_1986.pdf

[10] Schuster G., Löffer G., Weigl K., Hofbauer H.: Biomass steam gasification - an extensive parametric modeling study. Bioresource Technology, 77/1. (2001) 71-79.

https://doi.org/10.1016/S0960-8524(00)00115-2 